\title{
Avaliação de indicadores para classificação de florestas com elevado valor de conservação no Planalto Sul Catarinense
}

\author{
Evaluation of indicators for classification of forests with high conservation value \\ in the Southern Plateau of Santa Catarina State
}

\author{
Larissa de Souza Collet ${ }^{1}$ \\ Renata Diane Menegatti ${ }^{2(*)}$ \\ Lauri Amândio Schorn ${ }^{3}$
}

\section{Resumo}

Objetivou-se com este trabalho avaliar o uso de três grupos de indicadores ambientais, sendo eles: a composição vegetal, a fauna e aspectos da ecologia de paisagem na quantificação e qualificação de Florestas com Alto Valor de Conservação (FAVC), em três fazendas de um empreendimento florestal, instalado no Planalto Sul Catarinense. Para isso, realizou-se a caracterização da flora em unidades amostrais de $500 \mathrm{~m}^{2}$, demarcadas aleatoriamente, enquanto a amostragem da fauna foi realizada por armadilhamento fotográfico, busca ativa por vestígios e relatos de visualização ocasionais. A caracterização da ecologia da paisagem foi realizada através da análise de imagens ao longo do tempo. As variáveis consideradas para a definição de FAVC foram: estrutura da paisagem, \% de florestas em estágios avançados, presença de espécies da fauna e/ou flora com algum grau de ameaça e riqueza da fauna e/ou flora. Os indicadores ambientais da flora, fauna e ecologia da paisagem são capazes de indicar FAVC. Uma forte correlação entre os níveis de diversidade (H') e riqueza $(\mathrm{R})$ da fauna com a estrutura da vegetação arbórea e com as métricas da ecologia da paisagem sugerem que a combinação dos indicadores são capazes de definir áreas prioritárias para conservação em florestas do Planalto Sul Catarinense.

Palavras-chave: áreas prioritárias, certificação florestal, conservação.

\section{Abstract}

The objective of this study was to evaluate the use of three groups of environmental indicators: vegetal composition, fauna and aspects of landscape ecology in the quantification and qualification of Forests with High Conservation Value (HCVF) in three farms of a forestry enterprise installed in the Santa Catarina State Southern Plateau. For this, the characterization of the flora in $10 \times 50 \mathrm{~m}\left(500 \mathrm{~m}^{2}\right)$ sample units, randomly alocated, the fauna sampling was performed by photographic trapping, active search for traces and occasional reports. The characterization of the landscape ecology was carried out through the analysis of images over time. The variables considered for the definition of HCVF were: structure of the landscape, \% of forests in advanced stages,

I Msc.; Engenheira Florestal; Universidade Regional de Blumenau, FURB; Endereço: Rua São Paulo, 3520, CEP: 89030-000; Blumenau-SC, Brasil; E-mail: laricollet@gmail.com

2 Dra.; Engenheira Florestal; Universidade Federal de Pelotas; Endereço: s/n, C.P. 345. Capão do Leão, CEP: 960 I0-900, Pelotas-RS, Brasil; E-mail: renata.d.menegatti@gmail.com; (*) Autor para correspondências

3 Dr.; Engenheiro Florestal; Professor da Universidade Regional de Blumenau, FURB, Centro de Ciências Tecnológicas; Endereço: Rua São Paulo, 3520, CEP: 89030-000; Blumenau-SC, Brasil; E-mail: lauri.schorn@gmail.com

Recebido para publicação em 28/05/2019 e aceito em II/I2/2019

\begin{tabular}{llllll}
\hline Ambiência & Guarapuava (PR) & v.l5 n.2 & p. $444-456$ & Maio/Ago 2019 & ISSN I808 - 025I
\end{tabular}


presence of species of fauna and/or flora with some degree of threat and richness of fauna and/or flora. The environmental indicators of flora, fauna and landscape ecology are able to indicate HCVF. A strong correlation between the levels of diversity $\left(\mathrm{H}^{\prime}\right)$ and richness $(\mathrm{R})$ of the fauna with the tree vegetation structure and the landscape ecology metrics suggest that the combination of the indicators are able to define priority areas for forest conservation in the Santa Catarina State Southern Plateau.

Keywords: priority areas, forest conservation, conservation.

\section{Introdução}

O setor de base florestal pode ser descrito como um importante componente da economia brasileira, por contribuir de forma significativa para a geração de produtos, tributos, empregos e renda (CNI, 2017). No que tange ao setor florestal madeireiro, o estado de Santa Catarina tem expressiva participação, tanto pelo relevante número de empreendimentos florestais instalados principalmente na região do Planalto Catarinense, como também pelos altos índices de produtividade alcançados com o manejo silvicultural de espécies tradicionalmente cultivadas (ACR, 2016).

Recentemente o setor privado, além de prezar pela excelência no manejo florestal com vistas à produtividade, também vem conduzindo esforços em práticas de gestão ambiental, a partir da caracterização das interações entre os plantios comerciais que envolvem o empreendimento e os principais impactos ambientais envolvidos, especialmente aqueles referentes à diversidade biológica (JENNINGS et al., 2003). O aprimoramento nas práticas de gestão que buscam tornar a atividade mais sustentável, tanto no que tange ao setor produtivo, quanto ao conservacionista, tem por objetivo superior, atender à legislação vigente no contexto da Certificação Florestal.

A certificação florestal é subsidiada a empresas que buscam aliar as práticas de produtividade máxima à redução de impactos negativos, considerando políticas de conservação, fatores estes, excepcionalmente considerados na exportação de produtos de origem florestal para países desenvolvidos, bem como, nas relações com novos parceiros econômicos (SANTOS et al., 2017). O sistema Forest Stewardship Council (FSC ${ }^{\circledR}$ ) é um sistema de certificação de manejo florestal, regido a partir de princípios, critérios e indicadores, os quais elencam os elementos essenciais para o manejo florestal, bem como as questões de legalidade, a demanda do mercado e a qualidade final do produto (SPATHELF; MATTOS; BOTOSSO, 2004; MORAES; PUGLIESI, 2014).

Dentre os requisitos para a obtenção da $\mathrm{FSC}^{\circledR}$ está a necessidade de identificar e caracterizar Florestas de Alto Valor de Conservação (FAVC)(JENNINGS et al., 2003), inseridas dentro do empreendimento ou no entorno. Essa definição dará suporte para a criação de unidades de conservação, ou indicará locais mais propícios à manutenção e à conservação dos fragmentos naturais do entorno (RYLANDS; BRANDON, 2005; BRANDÃO et al., 2011), fortalecendo a visão conservacionista do empreendimento.

São consideradas FAVC aqueles fragmentos de floresta nativa que estão vinculados a três questões: importância ecológica, valor econômico e valor cultural, os quais possuem um significado relevante ou uma importância crítica. Para a definição de FAVC, atualmente são utilizados princípios estabelecidos pelo sistema $\mathrm{FSC}^{\circledR}$, que consideram atributos relacionados à presença de áreas protegidas, espécies ameaçadas ou em perigo de extinção, espécies endêmicas, ecossistemas raros, áreas com serviços ambientais básicos em situações críticas, áreas que subsidiam necessidades 
básicas às populações ou relacionadas à identidade cultural de determinadas comunidades (JENNINGS et al., 2003).

De acordo com Paiva et al. (2015), FAVC são caracterizadas por apresentarem espécies vegetais raras, composições faunísticas diferenciadas e processos pontuais de interesse ecológico da paisagem. Os atributos e critérios empregados na definição de FAVC são amplos e, no Brasil, ainda não existem índices para definições nacionais de FAVC. Considerando a grande diversidade dos biomas do Brasil, sugere-se que sejam considerados atributos intrínsecos da formação vegetal em análise, pois só assim será possível contemplar caracteres considerados importantes para a conservação local, que englobem a estrutura da vegetação, da riqueza e abundância da fauna e a interação desses componentes com a paisagem.

Diante dessas questões, objetivou-se com este trabalho avaliar o uso de três grupos de indicadores ambientais, sendo eles: a composição vegetal, a fauna e aspectos da ecologia de paisagem na quantificação e qualificação de FAVC em três fazendas de um empreendimento florestal instalado no Planalto Sul Catarinense

\section{Material e Métodos}

Para realização do estudo, foram selecionadas três áreas pertencentes à empresa Florestal Gateados Ltda, localizadas no Planalto Sul Catarinense, mais precisamente nos municípios de Campo Belo do Sul (Fazendas Morro Agudo e Guamirim Gateados) e Capão Alto (Fazenda Picaços), as quais estão inseridas na formação florestal denominada Ombrófila Mista (FOM).

A caracterização da flora e fauna foram realizadas por meio de um convênio entre a Universidade Regional de Blumenau - FURB e a proprietária das áreas onde os estudos foram realizados, no período entre 2012 a 2016.

O levantamento florístico foi realizado a partir de inventário florestal, em unidades amostrais de 10 x $50 \mathrm{~m}\left(500 \mathrm{~m}^{2}\right)$, aleatoriamente demarcadas, em número de 40, respectivamente, nas três fazendas indicadas anteriormente, com identificação de todas as árvores com DAP superior a 50,0 centímetros, a campo, com o devido nome popular, nome científico e família. Quando necessário, o material vegetal era coletado e conduzido ao laboratório para confecção de exsicatas para posterior identificação nos herbários da Universidade Regional de Blumenau (FURB) e Herbário LUSC da Universidade do Estado de Santa Catarina (UDESC). Pesquisas referentes a nomenclaturas atuais foram realizadas na Flora do Brasil (2014), Missouri Botanical Garden (2014) e New York Botanical Garden (2014).

A diversidade de espécies vegetais foi calculada através do índice de Shannon (H') e Índice de Equabilidade de Pielou (J) (MAGURRAN, 2004). Ao final, foram registradas e consideradas sete variáveis da vegetação: extensão da fazenda (ha), média de área basal dos indivíduoas amostrados ( $\mathrm{m}^{2} / \mathrm{ha}$ ), riqueza ( $\mathrm{n}^{\circ}$ de espécies), índice de diversidade de Shannon-Weaver $\left(\mathrm{H}^{\prime}\right)$, índice de equabilidade de Pielou (J) (MAGURRAN, 2004), porcentagem de floresta em estágio sucessional avançado ou floresta primária e o número de espécies com algum grau de ameaça de extinção, conforme a Lista de Espécies da Flora do Brasil (2016) e Lista Oficial das Espécies da Flora Brasileira Ameaçada de Extinção (MMA, 2014).

A amostragem da fauna foi dividida em mastofauna de médio e grande porte, o qual seguiu um conjunto de três metodologias: (1) armadilhamento fotográfico, (2) busca ativa por vestígios e registro direto e (3) encontros ocasionais por funcionários das empresas. 
Foram utilizadas armadilhas fotográficas digitais, buscas de evidências diretas (visualização, vocalização, carcaças e animais atropelados), evidências indiretas (pegadas, fezes, tocas) e foram percorridos transectos lineares pré-existentes (estradas e trilhas) de acordo com metodologia proposta por Picinatto Filho e Raffi (2016).

Nas fazendas, as armadilhas fotográficas foram distribuídas aleatoriamente por 30 estações de coleta de dados, sendo estas divididas em ambientes de mata nativa e plantio florestal. As armadilhas fotográficas foram instaladas em árvores ou estacas, a aproximadamente $50 \mathrm{~cm}$ do solo, mantidas em funcionamento 24 horas/dia, ajustadas para um intervalo mínimo entre capturas de 10 e/ou 30 segundos, pelo período de coleta de 48 meses (PICINATTO FILHO; RAFFI, 2016).

A caracterização e identificação da fauna visualizada e/ ou registrada nas trilhas, estradas e armadilhas a campo também foram realizadas com o devido nome popular, nome científico e família. Para a fauna geral, também foram descritas as espécies que apresentavam grau de ameaça conforme a lista oficial de espécies da fauna ameaçadas de extinção (MMA, 2014). Também foram analisadas as guildas tróficas, com base na similaridade no uso de recursos pelas espécies, nos seguintes tipos de dieta: Ca: Carnívoro; Fr: Frugívoro; Fo: Folívoro; Hb: Herbívoro; Gr: Granívoro; In: Insetívoro; Mir: Mirmecófago; On: Onívoro; Ps: Piscívoro.

A diversidade de espécies animais foi calculada através do índice de Shannon (H') e Índice de equabilidade de Pielou (J) (MAGURRAN, 2004). Para análise da fauna, foram estabelecidas cinco variáveis: equabilidade de Pielou $(\mathrm{J})$, número de guildas tróficas, riqueza ( $\mathrm{n}^{\circ}$ de espécies), diversidade $\left(\mathrm{H}^{\prime}\right)$, número de espécies com algum grau de ameaça.

A caracterização da ecologia da paisagem foi realizada pela visualização de imagens, a partir da configuração da paisagem, arranjos espaciais e da descaracterização de cada área ao longo do tempo. Para esse parâmetro, foram analisados fragmentos florestais que variaram em tamanho, e tiveram alterações nas características de borda. Foram determinadas, para cada fazenda, as seguintes métricas da paisagem: porcentagem de manchas, configuração da paisagem (porcentagem de vegetação natural), fragmentação do habitat (número de manchas) e tamanho médio das manchas (ha) (LANG; BLASCHKE, 2009).

Para a valoração das florestas em estudo foram sugeridos valores, considerando amplitudes máximas e mínimas para cada variável avaliada dentro dos três grupos de indicadores ambientais sendo eles: flora (Tabela 1), fauna (Tabela 2) e ecologia da paisagem (Tabela 3), distribuindo cada característica em diferentes classes de amplitude. As pontuações variaram de 1 até 5 , sendo a pontuação máxima para a vegetação 35 pontos, para a fauna 30 pontos e para a paisagem 25 pontos. Por fim, os valores obtidos para cada variável em cada fazenda foram somados para determinação das áreas florestadas com valores mais expressivos e, portanto, com maior valor de conservação.

De posse de todos os dados, foi aplicado o teste de correlação de Pearson entre a riqueza e a diversidade da fauna com as variáveis da vegetação e com as métricas da ecologia da paisagem. Utilizou-se a riqueza e a diversidade da mastofauna, pois são considerados indicadores do estado de conservação das florestas (POGGIANI; OLIVEIRA, 1998).

\section{Resultados e Discussão}

$\mathrm{Na}$ Tabela 4 podem-se observar os valores obtidos para os parâmetros vegetacionais avaliados em cada uma das três fazendas avaliadas. Nota-se a elevada discrepância na extensão total das fazendas $\left(\mathrm{m}^{2}\right)$ avaliadas, entretanto os demais parâmetros vegetacionais analisados demonstraram 


\section{Tabela 1. Parâmetros vegetacionais considerados na determinação de Florestas de Alto Valor de Conservação (FAVC) em três fazendas de um empreendimento florestal instalado no Planalto Sul Catarinense.}

\begin{tabular}{cccccc}
\hline & \multicolumn{7}{c}{ Pontuação } \\
\cline { 2 - 6 } Variáveis & 1 & 2 & 3 & 4 & 5 \\
Extensão da Fazenda $\left(\mathrm{m}^{2}\right)$ & $\geq 50$ & $51-250$ & $251-500$ & $500-1.000$ & $<1.000$ \\
Área Basal $\left(\mathrm{m}^{2}\right)$ & $\geq 10$ & $10-15$ & $15-20$ & $20-25$ & $<25$ \\
Riqueza (n' de espécies) & $\geq 20$ & $20-50$ & $51-100$ & $101-150$ & $<150$ \\
Diversidade (H') & - & $\geq 2.0$ & $2.0-3.0$ & $3.1-4.0$ & $<4.1$ \\
Equabilidade (J) & - & $0.2-0.39$ & $0.4-0.59$ & $0.6-0.79$ & $0.8-1.0$ \\
Estágio sucessional (A) ou FP (\%) & $\geq 20$ & $21-39$ & $40-59$ & $60-79$ & $<80$ \\
Grau de ameaça & $\geq 1$ & $2-4$ & $3-6$ & $7-9$ & $<10$ \\
\hline
\end{tabular}

Onde: A (Avançado); FP (floresta primária).

\section{Tabela 2. Características de fauna (mastofauna) consideradas para a determinação de Florestas de Alto Valor de Conservação (FAVC) em três fazendas de um empreendimento florestal instalado no Planalto Sul Catarinense.}

\begin{tabular}{cccccc}
\hline & \multicolumn{5}{c}{ Parâmetros de fauna } \\
\cline { 2 - 6 } Variáveis & 1 & 2 & 3 & 4 & 5 \\
Equabilidade (J) & - & $0.2-0.39$ & $0.4-0.59$ & $0.6-0.79$ & $0.8-1.0$ \\
Número de guildas tróficas & - & $1-3$ & $4-5$ & $6-7$ & 8 \\
Riqueza (no de espécies) & $\geq 5$ & $6-10$ & $11-15$ & $16-20$ & $<20$ \\
Diversidade (H') & - & $\geq 2.0$ & $2.0-3.0$ & $3.1-4.0$ & $\leq 4.1$ \\
Estágio sucessional A ou FP (\%) & $\geq 20$ & $21-39$ & $40-59$ & $60-79$ & $\leq 80$ \\
Grau de ameaça & $\geq 1$ & $2-4$ & $3-6$ & $7-9$ & $\leq 10$ \\
\hline
\end{tabular}

Onde: A (Avançado); FP (floresta primária).

certa similariedade. $\mathrm{O}$ maior diferencial foi obtido para a variável riqueza (número de espécies) entre as fazendas Picaços e a Guamirim Gateados, sendo estes , 73 e 86 respectivamente.

A análise dos índices de diversidade utilizados demonstra que, quanto maior a riqueza, maiores tendem a ser os valores de diversidade de espécies do tratamento das fazendas. Esse comportamento é usual em formações florestais denominadas ombrófila mista, e demonstra que, quanto maior a riqueza de espécies de uma comunidade vegetal, maior tende a ser a dominância de uma espécie em específico (PSCHEIDT et al., 2018).

No que se refere ao índice de riqueza, por demonstrar certa distinção entre as áreas, este pode ser sugerido como ferramenta na determinação de FAVC. A determinação da riqueza e da diversidade de espécies, em número,é essencial para reconhecer o estado atual do fragmento florestal, em relação às atividades impactantes do entorno, aos interesses e necessidades de conservação de recursos naturais ou à necessidade de recuperação de áreas degradadas (MELO, 2008). 
Tabela 3. Parâmetros da ecologia da paisagem considerados para a determinação de Florestas de Alto Valor de Conservação (FAVC) em três fazendas de um empreendimento florestal instalado no Planalto Sul Catarinense.

\begin{tabular}{|c|c|c|c|c|c|}
\hline \multirow[b]{3}{*}{ Variáveis } & \multicolumn{3}{|c|}{ Parâmetros da ecologia da paisagem } & & \multirow[b]{3}{*}{5} \\
\hline & \multicolumn{4}{|c|}{ Pontuação } & \\
\hline & 1 & 2 & 3 & 4 & \\
\hline Manchas (\%) & $\leq 81$ & $51-250$ & $41-60$ & $21-40$ & $\geq 20$ \\
\hline $\begin{array}{c}\text { Configuração } \\
\text { da paisagem (\%) }\end{array}$ & $\begin{array}{l}\geq 20 \% \text { de } \mathrm{Ne} \\
80 \% \mathrm{R}+\mathrm{O}\end{array}$ & $\begin{array}{l}21-39 \% \text { de } \mathrm{N} 60- \\
79 \% \text { de } \mathrm{R}+\mathrm{O}\end{array}$ & $\begin{array}{l}41-59 \% \text { de } \\
\text { N e R+O }\end{array}$ & $\begin{array}{c}60-79 \% \text { de } \\
\text { N e } 21-39 \% \\
\text { R+O }\end{array}$ & $\begin{array}{l}\leq 80 \% \text { de } \\
\mathrm{N} \text { e } \mathrm{R}+\mathrm{O}\end{array}$ \\
\hline $\begin{array}{l}\text { Fragmentação de habitats } \\
\qquad\left(n^{\circ} \text { de manchas }\right)\end{array}$ & $\leq 80$ & $60-79$ & $40-59$ & 21-39 & $\geq 20$ \\
\hline $\begin{array}{c}\text { Tamanho médio } \\
\text { das manchas (hectares) }\end{array}$ & - & $\begin{array}{l}\text { 0-200 } \\
\text { Muito Pequenas }\end{array}$ & $\begin{array}{l}201-500 \\
\text { Pequenas }\end{array}$ & $\begin{array}{l}501-1.000 \\
\text { Médias }\end{array}$ & $\begin{array}{l}<1.000 \\
\text { Muito } \\
\text { Grande }\end{array}$ \\
\hline $\begin{array}{c}\text { Estágio sucessional } \\
\text { A ou FP }(\%)\end{array}$ & $\geq 20$ & $21-39$ & $40-59$ & $60-79$ & $\leq 80$ \\
\hline
\end{tabular}

Sendo: $N$ (fragmento de floresta nativa); $R$ (fragmento de reflorestamento); $O$ (outras áreas, por exemplo:plantio agricola e benfeitorias).

Tabela 4. Valores obtidos para os parâmetros vegetacionais considerados para a determinação de Florestas de Alto Valor de Conservação (FAVC) em três fazendas de um empreendimento florestal instalado no Planalto Sul Catarinense.

\begin{tabular}{cccc}
\hline & \multicolumn{2}{l}{ Parâmetros vegetacionais } \\
Variável & $\begin{array}{l}\text { Morro } \\
\text { Agudo }\end{array}$ & Picaços & Guamirim Gateados \\
\hline $\begin{array}{c}\text { Extensão da Fazenda } \\
\left(\mathrm{m}^{2}\right)\end{array}$ & 299 & 3653 & 12866 \\
$\begin{array}{c}\text { Área Basal média }\left(\mathrm{m}^{2}\right) \\
\text { Riqueza }\left(\mathrm{n}^{\circ} \text { de }\right.\end{array}$ & 44.4 & 47.02 & 42.01 \\
$\quad$ espécies $)$ & 77 & 73 & 86 \\
$\begin{array}{c}\text { Diversidade }\left(\mathrm{H}^{\prime}\right) \\
\text { Equabilidade }(\mathrm{J})\end{array}$ & 3.5 & 3.56 & 3.66 \\
Estágio sucessional & 0.79 & 0.81 & 0.81 \\
A ou FP (\%) & $<50$ & $<50$ & $<50$ \\
Grau de ameaça & 1 & 3 & 3 \\
\hline
\end{tabular}

Onde: A (Avançado); FP (floresta primária).

Quanto à caracterização da fauna, de acordo com a tabela 5, pode-se notar maior variação entre as fazendas, principalmente quanto à riqueza, diversidade e grau de ameaça das espécies animais. Sendo a fazenda Guamirim Gateado, descrita como de maior extensão, aquela que apresentou superioridade para todos esses índices referentes a fauna.

Ressalta-se que, possívelmente, a fazenda Guamirim Gateados, por possuir maior riqueza de espécies vegetais, atrai maior número de espécies animais com certo grau de

COLLET, L. S., MENEGATTI, R. D., SCHORN, L. A. 
Tabela 5. Valores obtidos para as características da fauna consideradas para a determinação de Florestas de Alto Valor de Conservação (FAVC) em três fazendas de um empreendimento florestal instalado no Planalto Sul Catarinense.

\begin{tabular}{cccc}
\hline & \multicolumn{2}{c}{ Parâmetros de Fauna } & \\
Variável & Morro Agudo & Picaços & Guamirim Gateados \\
\hline Equabilidade (J) & 0.72 & 0.83 & 0.72 \\
Número de guildas tróficas & 8 & 8 & 8 \\
Riqueza (n ${ }^{\circ}$ de espécies) & 14 & 14 & 22 \\
Diversidade (H') & 1.79 & 2.09 & 2.25 \\
Grau de ameaça & 14 & 14 & 22 \\
\hline
\end{tabular}

\section{Tabela 6. Valores obtidos para as variáveis da ecologia da paisagem consideradas para a determinação de Florestas de Alto Valor de Conservação (FAVC) em três fazendas de um empreendimento florestal instalado no Planalto Sul Catarinense.}

Parâmetros da ecologia da paisagem

\begin{tabular}{cccc} 
Variável & Morro Agudo & Picaços & Guamirim Gateados \\
\hline Manchas (\%) & 40 & 45 & 70 \\
Configuração da paisagem (\%) & 60 & 55 & 30 \\
$\begin{array}{c}\text { Fragmentação de habitats } \\
\text { (no de manchas) }\end{array}$ & 5 & 9 & 25 \\
$\begin{array}{c}\text { Tamanho médio das manchas } \\
\text { (hectares) }\end{array}$ & 452.9 & 160.3 & 108.1 \\
\hline
\end{tabular}

ameaça e, por isso, sugere-se que esta deve ser priorizada na determinação de FAVC por poder abrigar espécies raras ou endêmicas.

Na tabela 6, podem-se observar os valores obtidos para os parâmetros da ecologia de paisagem de cada uma das três fazendas do empreendimento florestal instalado no Planalto Sul Catarinense. Analisando os parâmetros é possível verificar que a fazenda Guamirim Gateados é constituída de um elevado número de manchas, e essas manchas possuem um tamanho médio considerado inferior, quando comparado às demais fazendas avaliadas.

Dados do Inventário Florístico Florestal de Santa Catarina (IFFSC), publicados por Vibrans et al. (2011), mostram que a maior parte dos remanescentes florestais da floresta ombrófila mista se encontra na forma de fragmentos florestais, bastante degradados devido principalmente à intensa exploração antrópica. A fragmentação florestal é um processo em que as florestas contínuas são repartidas em fragmentos de menor extensão e, dessa forma, isoladas do habitat original, forçando a perda da biodiversidade e até a extinção facilitada de espécies endêmica e raras (BRITEZ et al., 2003).

Considerando os três grupos de indicadores ambientais, composição vegetal, fauna e aspectos da ecologia de paisagem, podemos concluir que entre as variáveis de maior relevância 
para definir florestas de elevado valor para conservação encontram-se: a riqueza de espécies vegetais, a diversidade da fauna e a presença de animais com algum grau de ameaça, o número de manchas e o tamanho das manchas.

$\mathrm{Na}$ tabela 7 estão descritas as pontuações individuais e acumuladas para os parâmetros vegetacionais, características da fauna e variáveis da ecologia da paisagem por cada uma das três fazendas de um empreendimento florestal instalado no Planalto Sul Catarinense.

\section{Tabela 7. Pontuações obtidas para os parâmetros vegetacionais, características da fauna e variáveis da ecologia da paisagem consideradas para a determinação de Florestas de Alto Valor de Conservação (FAVC) para cada uma das três fazendas de um empreendimento florestal instalado no Planalto Sul Catarinense.}

\begin{tabular}{ccccc}
\hline \multirow{2}{*}{ Fazenda } & \multicolumn{3}{c}{ Parâmetro } & \multirow{2}{*}{ Pontuação Total } \\
\cline { 2 - 4 } & Vegetacional & Fauna & Paisagem & 59 \\
\hline $\begin{array}{c}\text { Fazendo } \\
\text { Morro Agudo }\end{array}$ & 26 & 17 & 16 & \\
$\begin{array}{c}\text { Fazenda } \\
\text { Picaços }\end{array}$ & 28 & 20 & 13 & 61 \\
$\begin{array}{c}\text { Fazenda } \\
\text { Guamirim } \\
\text { Gateados }\end{array}$ & 27 & 21 & 10 & 58 \\
\hline
\end{tabular}

A Fazenda Picaços exibiu valores superiores para a soma de atributos das variáveis do componente arbóreo, pois se trata de floresta em estágio avançado de regeneração e àquelas relacionadas às variáveis da fauna que, no fim, contribuiram positivamente para maior pontuação total para esta fazenda.

Entretanto comparando a soma total da fazenda Picaços com as demais fazendas avaliadas, não foi possível observar diferença satisfatória para distinguir as áreas e determinar possíveis FAVC. De forma geral, considerando o exposto e cada grupo isoladamente, a fazenda Guamirim Gateados, de maior extensão territorial, também possui fragmentos de floresta nativa em maior número e menor tamanho, configurando uma forte fragmentação de habitats, porém, por ser possuidor de maior riqueza de espécies vegetais, atrai maior número de espécies animais com certo grau de ameaça, podendo ser indicada com maior credibilidade para a determinação de FAVC.

A partir da classificação das variáveis nos três grupos, estrutura do componente arbóreo, fauna e ecologia da paisagem, foram destacadas (Tabela 6) as variáveis com maior valoração em cada fazenda, evidenciando aquelas que podem contribuir para a definição de florestas de alto valor de conservação.

Os resultados da correlação da diversidade ( $\left.\mathrm{H}^{\prime}\right)$ e a riqueza $(\mathrm{R})$ da fauna com as variáveis da estrutura da vegetação arbórea e com as métricas da ecologia da paisagem estão apresentadas nas Figuras 1 e 2. Para essas análises, foram excluídos o número de guildas tróficas (NG) e o número de espécies com algum risco de extinção, pois os valores para essas variáveis foram iguais nas três fazendas.

COLLET, L. S., MENEGATTI, R. D., SCHORN, L. A. 


\section{Tabela 8. Variáveis de maior valor de importância para a determinação de Florestas de Alto Valor de Conservação (FAVC) em cada uma das três fazendas de um empreendimento florestal instalado no Planalto Sul Catarinense.}

\begin{tabular}{ccc}
\hline Fazenda & Pontuação Total & Variáveis relevantes \\
\hline Morro Agudo & 59 & $\begin{array}{c}\text { Diversidade da flora, equabilidade da flora e fauna, } \\
\text { extensão, área basal, \% de floresta em estágio avançado/ } \\
\text { primária, número de guildas tróficas, estrutura da } \\
\text { paisagem, baixa fragmentação de habitats. }\end{array}$ \\
Picaços & Baixa fragmentação de habitats, espécies da fauna com \\
algum grau de ameaça, equabilidade da fauna e flora, \\
número de guildas tróficas, área basal, diversidade da flora. \\
Guamirim \\
Gateados
\end{tabular}

Figura 1. Correlações entre a diversidade (A) e a riqueza (B) da fauna com as seguintes variáveis da estrutura da vegetação arbórea EXT (extensão da fazenda, em ha), AB (área basal, em $\mathrm{m} 2 / \mathrm{ha}$ ), $R$ (riqueza ou número de espécies), $H^{\prime}$ (índice de diversidade de Shannon-Weaver) e J (índice de equabilidade de Pielou).
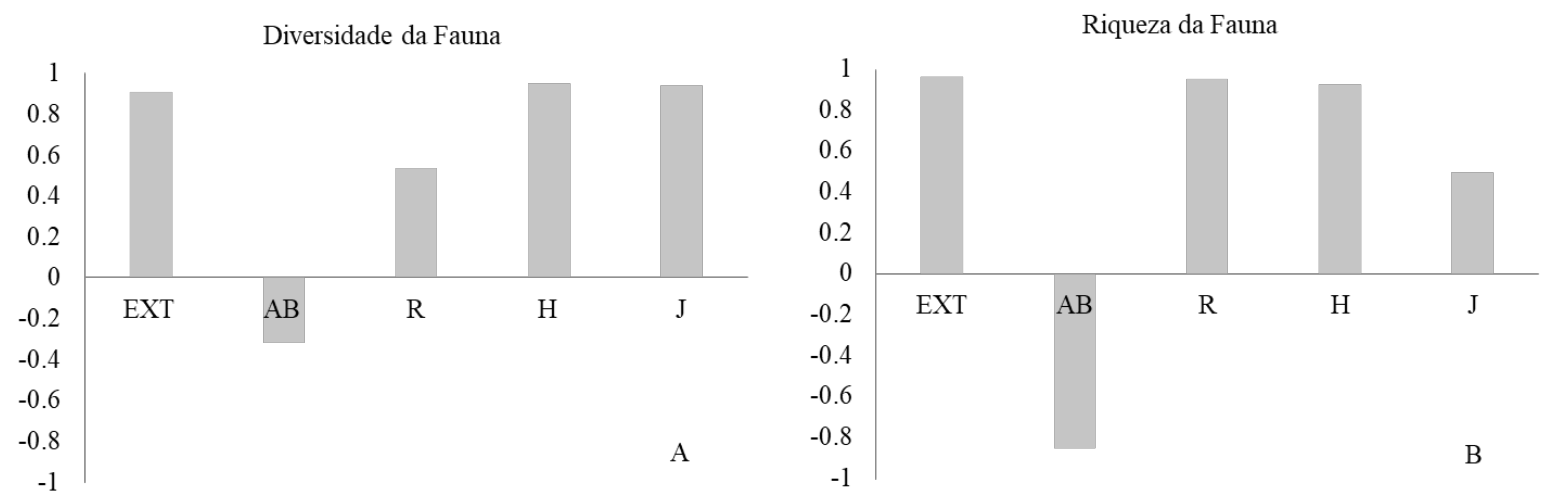

A extensão das fazendas, bem como a diversidade ( $\left.H^{\prime}\right)$ da vegetação apresentaram correlações elevadas e positivas, superiores a 0,9 , tanto com a diversidade quanto com a riqueza da fauna. Também se destacaram a equabilidade da vegetação arbórea com a diversidade da fauna e a riqueza da vegetação arbórea com a riqueza da fauna, também correlacionando-se positivamente. Por outro lado, a área basal da vegetação arbórea (AB) mostrou resultados diferentes em relação às demais variáveis, apresentando correlações negativas tanto com a diversidade quanto com a riqueza da fauna.

Houve correlação positiva entre a porcentagem de área ocupada por reflorestamento e outros usos com a diversidade da fauna. $\mathrm{O}$ mesmo fato ficou evidenciado para o número de manchas (NM) e o tamanho médio das manchas (MTM). Por outro lado, a porcentagem de manchas, ou 
Figura 2. Correlações entre diversidade (A) e riqueza (B) da fauna com as métricas da ecologia de paisagem porcentagem de manchas $(\% M)$, de áreas ocupadas com outros usos $(\% \mathrm{~N})$, número de manchas (NM) e média do tamanho de manchas (MTM, em ha).
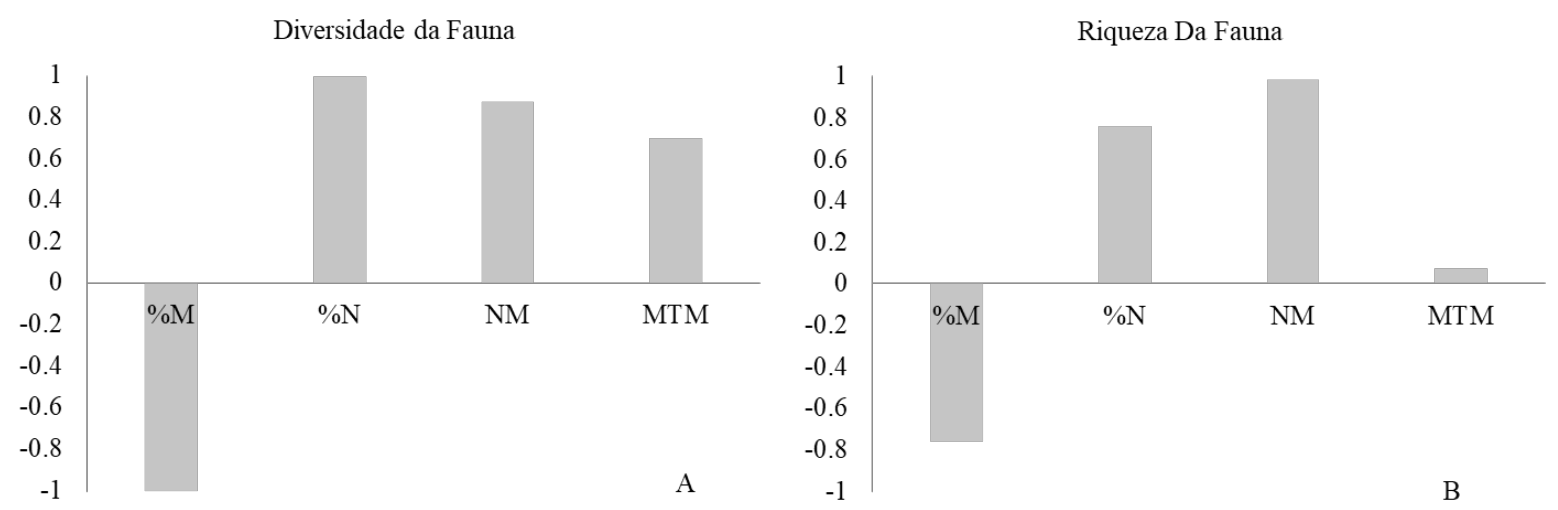

seja, a fragmentação das áreas com floresta natural resultaram em correlações negativas elevadas, tanto com a diversidade quanto com a riqueza da fauna (Figura 2).

Os resultados do estudo mostraram que a fragmentação das florestas pode representar ameaças para a mastofauna, conforme correlações verificadas entre variáveis da fauna e tamanho dos remanescentes florestais. As correlações elevadas e positivas entre a diversidade e a riqueza da mastofauna com a extensão das áreas evidencia isso.

Diversos autores citaram que a fragmentação de habitats é considerada uma das maiores ameaças à conservação da biodiversidade (CROOKS; SANJAAYAN, 2006; BRASIL, 2006). Observou-se nesta pesquisa que os padrões dos elementos da paisagem, caracterizados como manchas de florestas naturais influenciaram fortemente nas variáveis da mastofauna e da estrutura da vegetação.

A correlação negativa apresentada para $\% \mathrm{M}$ e riqueza e diversidade da fauna sugere que ambientes heterogêneos podem contribuir para aumentar esses atributos da mastofauna. Isso significa que esse grupo de espécies pode ser beneficiado também por clareiras ou ambientes abertos, locais onde encontram recursos para sua sobrevivência.

Pscheidt et al. (2018) sugeriram que um longo histórico de perturbações nas áreas de Floresta Ombrófila Mista no sul do Brasil pode ter resultado em um processo de homogeneização biológica, de forma que, em pequena escala espacial, não seria possível identificar diferenças florísticas e estruturais entre a borda e o interior dos remanescentes. Esse fato contribui para explicar a maior diversidade e riqueza da mastofauna em áreas com maior \% de manchas, no presente estudo.

As variáveis da estrutura da floresta, bem como as métricas da paisagem, utilizadas neste estudo apresentaram forte relação com a riqueza e a diversidade da mastofauna, podendo, portanto, serem utilizadas para qualificar florestas quanto ao valor de conservação.

\section{Conclusões}

O emprego dos indicadores ambientais da flora, fauna e ecologia da paisagem de forma isolada são capazes de determinar florestas de Alto Valor de Conservação no Planalto Sul Catarinense.

COLLET, L. S., MENEGATTI, R. D., SCHORN, L. A. 
A correlação entre os níveis a diversidade ( $\left.H^{\prime}\right)$ e riqueza $(R)$ da fauna com a estrutura da vegetação arbórea e com as métricas da ecologia da paisagem sugerem que a combinação dos indicadores são capazes de definir áreas prioritárias para conservação em florestas do Planalto Sul Catarinense.

\section{REFERÊNCIAS}

ACR. Associação Catarinense de Empresas Florestais. Anuário Estatístico de Base Florestal para o Estado de Santa Catarina 2016 (Ano Base 2015). Lages, SC. 2016.

BRANDÃO, C. F. L. S.; JUNIOR, F. T. A.; LANA, M. D.; MARANGON, J.C.; Feliciano, A. L. P. Distribuição espacial, sucessão e dispersão do componente arbóreo em remanescente de floresta atlântica, Igarassu, Pernambuco. Revista Verde, v. 6, n. 2, p. 218-229, 2011.

BRASIL. Ministério do Meio Ambiente. O corredor central da Mata Atlântica: uma nova escala de conservação da biodiversidade. Brasilia: Ministério do Meio Ambiente. 2006. 52 p.

BRITEZ, R. M.; ALGERK, B.; BAUMGARTEN, J. E.; CASTELLA, P. R.; CULLEN, L. J.; FARIA, D. M. Manejo do entorno. In: Rambaldi DM, Oliveira DAS, organizadores. Fragmentação de ecossistemas: causas, efeitos sobre a biodiversidade e recomendações de políticas públicas. Brasília: MMA: SBF; 2003.

CASTELLON, T. D.; SIEVING, K. E. An experimental test of matrix permeabbility and corridor use by endemic understory bird. Conservation Biology, v. 20, n. 1, p. 135-145, 2006.

CNI. Confederação Nacional da Indústria. Florestas plantadas: oportunidades e desafios da indústria de base florestal no caminho da sustentabilidade / Confederação Nacional da Indústria, Indústria Brasileira de Árvores - Brasília : CNI, 2017.

CROOKS, R.; SANJAYAN, M. Conectivity conservation. Cambridge University Press. 2006.

FLORA DO BRASIL. Jardim Botânico do Rio de Janeiro. Disponível em: http://floradobrasil. jbrj.gov.br/reflora. Acesso em: 31 mar. 2019.

HILTY, J. A.; LIDICKER, W. A.; MERENLENDER, A. M. Corridor Ecology: The science and practice of linking landscape for biodiversity conservation. Island Press, 2006.

JENNINGS, S.; NUSSBAUM, R.; JUDD, N.; EVANS, T. G. Guia para Florestas de Alto Valor de Conservação. $1^{\mathrm{a}}$ ed. HCVF Toolkit, 2003.

LISTA DE ESPÉCIES DA FLORA DO BRASIL. 2016. Projeto Reflora: flora do Brasil 2020. Disponível em http:// floradobrasil.jbrj.gov.br. Acesso em: 17 abr. 2016.

MINISTÉRIO DO MEIO AMBIENTE. Portaria nº 443, de 17 de dezembro de 2014. Espécies da Flora brasileira ameaçada de extinção. Ministério do Meio Ambiente, Brasília. 
MISSOURI BOTANICAL GARDEN. Disponível em: <http://www. missouribotanicalgarden.org/>. Acesso em: 31 mar. 2019.

LANG, S.; BLASCHKE, T. Análise da Paisagem com SIG. São Paulo: Oficina de Textos, p. 424, 2009.

LAURANCE, W. F. NASCIMENTO, H., LAURANCE, S.G., ANDRADE, A., RIBEIRO,J., GIRALDO,J.P., LOVEJOY,T.E., CONDIT, R., CHAVE, J.,D'ANGELO, S. Rapid decay of tree-community composition in Amazonian forest fragments. Proceedings of the National Academy of Sciences, v. 103, n. 50, p. 19010-19014, 2006.

MAGURRAN,A.E.Measuringbiological diversity. Oxford,Blackwell Science, p. 256, 2004.

MELO, A. S. O que ganhamos 'confundindo' riqueza de espécies e equabilidade em um índice de diversidade? Biota Neotrop., v. 8, n. 3, p.21-027, 2008.

MORAES, C. S. B. de; PUGLIESI, E. Auditoria e Certificação Ambiental. Curitiba: InterSaberes, p. 360, 2014.

NEW YORK BOTANICAL GARDEN. Disponível em:<https://www.nybg.org/>. Acesso em: 31 mar. 2019.

PAIVA, S. N. de.; SILVA, D. A. da, ROCHADELLI, R.; HOSOKAWA, R.T.; OSHIRO, C. R. A Certificação florestal pelo FSC ${ }^{\circledR}$ : um estudo de caso. Floresta, v. 45, n. 2, p. 213 - 222, 2015.

PICINATTO FILHO, V. RAFFI, M.F. Diagnóstico da Biodiversidade: Mastofauna de médio e grande porte. Sumatra: Inteligência Ambiental. Florestal Gateados Ltda, Campo Belo do Sul/SC, p. 2016.

POGGIANI, F.; OLIVEIRA, R.E. Indicadores para conservação dos núcleos de vida silvestre. Série técnica, v. 12, n. 31, p. 45-52, 1998.

PSCHEIDT, F.; HIGUCHI, P.; SILVA, A. C.; RECH, T. D.; SALAMI, BB.; FERREIRA, T. de S.; BONAZZA, M.; BENTO, M. A. Efeito de borda como fonte de heterogeneidade do componente arbóreo de uma floresta com Araucárias no sul do Brasil. Ciência Florestal, v. 28, n. 2, p. 601-612. 2018.

SANTOS,T.W.dos; PELISSARI,A.L.; SANQUETTA, C. R. Quantificação e distribuição espacial dos certificados florestais FSC no Brasil. Agrarian Academy, v. 4, n. 8, p. 228, 2017.

SEOANE, C. E. S.; DIAZ, V. S.; SANTOS, T. L.; FROUFE, L. C. M. Corredores ecológicos como ferramenta para a desfragmentação de florestas tropicais. Pesquisa Florestal Brasileira, v. 30, n. 63, p. 207-216, 2010.

SPATHELF, P.; MATTOS, P. P. de; BOTOSSO, P. C. Certificação florestal no Brasil uma ferramenta eficaz para a conservação das florestas naturais? Floresta, v. 34, n. 3, 2004. 
VIBRANS, A. C.; SEVEGNANI, L.; UHLMANNA, K.; SCHORN, L.A.; SOBRAL, M. G.; DE GASPERAL, R. Structure of mixed ombrophyllous forests with Araucaria angustifolia (Araucariaceae) under external stress in Southern Brazil. Revista de Biologia Tropical, n. 59, v. 3, p. 1371-1387, 2011. 